\title{
Investigating the e-Learning Training Need Analysis of the Faculty Members in a Business Department of a Tertiary Institution
}

\author{
Guek Young Vanda Kwek and Wing Sum Cheung
}

\begin{abstract}
This paper's goal is to identify the faculties' current skills on e-learning tools, Motivation levels, Incentives, Knowledge and Environment (henceforth MIKE) in a tertiary institution's Business department. This study investigates the faculties' training needs analysis and provides recommendations for e-learning training sessions.

A mixed method study was adopted and data was collected via two instruments: one-on-one semi-structured interview and via a 5 points Likert scale questionnaire. Ten faculties completed these two instruments consecutively. The one-on-one semi structured interview investigated the MIKE factors. The questionnaires investigated the faculties' current e-learning tools skill.

Under training needs, specific e-learning training sessions be tailored made for the motivated faculties. Additionally, under non-training needs, administrative, operational needs and support require adjustments.

This study's recommendations may benefit the management to consider improving the faculties' e-learning skills, knowledge and enhance students' overall learning experiences.
\end{abstract}

Index Terms - E-learning, training needs analysis.

\section{INTRODUCTION}

In a tertiary institution, an e-learning session is compulsory and takes up 1 week of the 13 weeks curriculum. As such, it is essential for faculties to possess some e-learning skills for effective implementation of the e-learning process. The aim of this study is to find out what types of training needs the faculties should have in order to design and develop interesting e-learning activities for the students.

\section{Problem Statement}

According to the Academic Experiential Survey (henceforth AES) conducted in April 2013 semester, students gave negative comments about their e-learning experiences. For example, e-learning lessons are "boring, disappointing, and unsatisfactory". The management is concerned about these comments. The management expects the faculties to generate e-learning activities that will engage and motivate students.

Manuscript received March 3, 2014; revised May 13, 2014.

Guek Young Vanda Kwek is with Institute of Technical Education, Singapore (e-mail: vanda_g_y_kwek@ite.edu.sg).

Wing Sum Cheung is with Nanyang Technological University-National Institute of Education, Singapore (e-mail: wingsum.cheung@nie.edu.sg).

\section{RESEARCH QUESTIONS}

1) What are the e-learning skills that the faculties have?

2) What types of support and training do faculties need to design and develop interesting activities?

\section{DEFinition OF E-LEARNING}

E-learning maybe defined as learning that is delivered, enabled or facilitated using electronic technology for training purpose, learning or development on organizations [1].

\section{BENEFITS AND DRAWBACKS OF E-LEARNING}

As in any modes of learning, there are several pros and cons in e-learning for students and faculties. For this section, it is essential to evaluate what works and what did not work for others.

The students' benefits are firstly, to have the opportunities to exchange views with their peers and lecturers online and retrieve documents on a portal for learning, ideas exchange, and submission of assignments amongst others [2]. Moreover, for the faculties, conducting e-learning is more interactive as compared to the traditional classroom interaction.

The drawbacks of e-learning to the students is given that there is reduced face-to-face communication, the actual communication sent cannot be assessed visually. As a result, misunderstanding of messages can happen [3]. Several commentators identified faculties' barriers for e-learning, the lack of user support and organization culture that maybe resistance to change [4].

The above information provided broad insights into the effects of e-learning that is beneficial for discussion under the Discussion and Recommendation sections.

\section{BACKGROUND OF THE TERTIARY INSTITUTION}

Located in South East Asia - Singapore, the institute has a strong focused on practice-based learning. There are 8 diplomas offered. The student population is about 15,000. In the Business school, for every semester, the students evaluate the modules, the faculties' teaching methods and delivery methods. In each semester, there is an e-learning week and each module must have an e-learning session. Given that the April 2013 AES reflected that certain faculty delivered e-learning sessions that were "boring, disappointing, and unsatisfactory". As such, the management is concerned about the unfavorable comments. They are interested to find out 
exactly what are the performance gaps, with the intention to narrow these gaps. No committee has ever done any investigation on the faculties' training needs analysis for the last 6 years.

\section{TERMINOLOGIES MIKE}

The 4 major terms of MIKE are used to establish the faculties' approaches toward designing and conducting e-learning (Refer to Table I on MIKE Terminologies).

\begin{tabular}{ll}
\multicolumn{2}{c}{ TABLE I: TERMINOLOGIES MIKE } \\
motivation & \multicolumn{1}{c}{ Definitions } \\
& indicates people's persistence of \\
& efforts. Two factors determined \\
& motivation: An individual's ability to \\
& name, list, and describe the reasons for \\
& doing something and his or her \\
& confidence levels [5]. \\
& refers to culture and it is linked to \\
& performance management metrics [5]. \\
& refers to capacity. The individual's \\
incentives & ability to do what is needed, to know \\
skills and knowledge & what s/he needs to know, to know \\
& where to search and discover what is \\
& necessary and how to manage \\
& opportunities and challenges [5]. \\
& related to an organization's policies, \\
& hardware, software and procedures \\
& [5].
\end{tabular}

\section{METHODOLOGY}

The Training Needs Analysis (TNA) as highlighted by Allison Rosette entails the MIKE model. In this paper, MIKE is used as a framework to design and execute semi structure interview and 5 points Likert scale questionnaire. In the later chapter, under Findings and Discussions, the implementation of the adopted TNA framework will be discussed in detail. The role of performance analysis is to identify the faculties' current e-learning skills. The function of TNA is to create tangible solution(s) to come up with e-learning courses and incentives amongst others to resolve the problems [6].

\section{LITERATURE REVIEW}

According to Literature Reviews, some e-learning tools are important for faculties in the execution of e-learning lessons [6]. Below are the e-learning tools used in the survey (Refer to Table II).

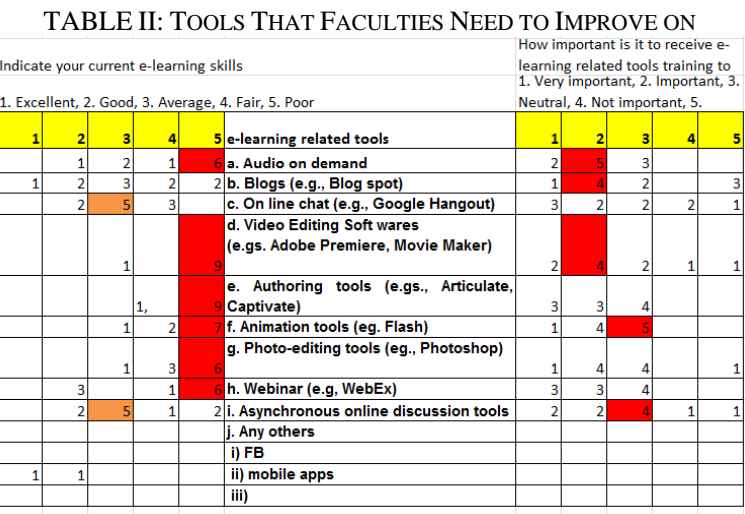

\section{Research Design}

\section{A. Procedure}

10 participants were interviewed. They were shown the Participant Information Sheet and Consent Form. Explanations were provided about the aim of the study, the purposes of the questionnaire and the interview. They were assured of the confidentiality of their contributions and lastly, requested to sign off the form, if agreed. Their years of teaching experience range from 1.5 to 28 years. New faculties were not included in this study, because they were not given module leadership for their first semester.

\section{B. Source of Data (Sampling)}

Convenience or opportunity sampling is used as the researcher and the faculties had geographical proximity and easily accessible.

\section{Instruments}

This study adopts two methods: 5 points Likert Scale and one-on-one interview.

In the Performance Analysis (PA) to TNA model, under the PA section, the optimal versus current seeks to draw out the performance gaps of the faculties' skills on e-learning tools. The results will determine what e-learning training sessions are needed.

This qualitative single-site case study was designed to investigate the training needs of the faculties. Case study approach is effective when the objective of the study is to gain a deeper insight of the training needs. In a qualitative research, the aim is to include the sentiments from the participants' perspectives. Given that there are several ways to implement e-learning, faculties share their thoughts on the e-learning training session arrangements. It was observed that the faculties did not know the functions of some e-learning tools and the researcher has to step in to provide explanations.

Semi-structured interviews were chosen because this method allowed the researcher to prove further and solicit narrative responses reflecting their personal encounters [3].

\section{Actual Data Analysis}

For the semi-structured interview, the answers were typed written, 10 members checking were done with minor amendments. The revised copies served as field notes.

For the questionnaire quantitative data, the faculties' "Excellent to Poor" e-learning tools skills were analyzed. After gathering the data on paper and pencil, using an Excel spread sheet, the data were entered from "Excellent to Poor" columns. For comparison purposes, these skills are termed as themes and compared with themes from the field notes. Both quantitative results and qualitative findings were developed into joint display tables for comparison to determine if the interview supports the questionnaire results [7]. For the qualitative findings, a thick description is used to present the result. The researcher provides an interpretation on the MIKE findings under the next section.

\section{FINDINGS AND DISCUSSION}

Results revealed that the performance gaps exist, the 
faculties did not have adequate e-learning skills to design and develop e-learning sessions.

Below are the findings of the actual performance, only the highlighted tools are further analysed as they are deemed to be more urgent for recommendation purpose.

\section{1) Actual performance (refer to Table II)}

In attempting to address the first research question, what are the e-learning skills that the faculties have? Below are the rankings:

In Audio on demand tool, six out of ten faculties indicated that they are at the poor scale. This could mean that during e-learning sessions, the students received the slides without the any voice over. Without any audio explanation, understanding of content may suffer. For receiving training, two out of ten and five out of ten faculties identified that audio on demand are very important and important tool respectively and supported the idea to receive such training.

In Video Editing Soft wares, nine out of ten faculties rated that they are poor on this skill set. The lack of knowledge makes it tough to know what tools to improve their lessons. In terms of training sessions, three out of ten and two out of ten faculties identified that it is very important and important respectively to undergo training.

Nine out of ten faculties responded that they have poor skill in Authoring tools. It is perhaps that there is a lack of exposure and awareness that such tools are available in the market. In terms of receiving e-learning training, three out of ten faculties indicated that it is very important and another three out of ten faculties rated it as important. This implied that they see positive learning effects to have audio, visuals, texts, pictures, animations, quizzes amongst others all packed into an e-learning package.

Seven out of ten faculties ranked their Animation skill as poor. This lack of skill indicated that there is a major limitation when the need arises to create graphically engaging visuals to engage students and to enhance learning. As such, this may confirm why students branded e-lessons as "boring and non-engaging." Only four out of ten faculties indicated that it is important to learn Flash.

With Photo-editing tool, six out of ten faculties rated themselves poor in this tool. Four out of ten faculties ranked that it is important to learn this skill for their e-learning activities. In some projects, there is need for students to submit visuals. This skill will come in handy for touch up purpose.

In Webinar tool, six out of ten faculties ranked themselves as having poor skill. This indicated that they had never conducted or never thought that there is such a tool available. Three out of ten faculties thought that it is very important and another three out of ten thought that it is important to receive this training. As such, they do see the value add that a webinar can offer to their e-learning plans, that is have a bigger group of students during the webinar and have them to do instant polls, read the slides and solicit for feedback amongst instantly.

To address the second research question, what types of support and training do lecturers need to design and develop interesting activities? Insights are developed base on code frequencies. Below are the findings:

\section{2) Attending e-learning sessions}

Majority of the faculties had attended $(\mathrm{Bb})$ related short courses, Web 2.0 tools and Collaborate for in-house program. These short courses were not compulsory.

\section{3) Knowledge, skills and information}

Six out of ten faculties indicated that they chose "not so difficult topics" when the started out in designing and developing e-learning topic. It could be interpreted a simple content, should be taught rather than what topic is suitable for e-learning conversion. Due to the lack of core e-learning tools skill as reflected on the findings above, this limitation perhaps made it hard to explore more suitable topics for e-learning.

\section{4) Motivations and feelings}

Four out of ten faculties desired to devote more time in building up their e-learning skills, though they did not specify how much time. Two out of ten faculties indicated at least 1 week, this implied that there is a motivation and openness to learning new tools. Ten faculties indicated that they would be interested to sign up for e-learning courses, if provided. It is inferred that learning new tools is important to them. Base on the questionnaire results on the training to receive section, there are some positive responses that will be discussed under Recommendation.

\section{5) Environment, tools and process}

Seven out of ten faculties opted for face-to-face training session if the institute provides them with classes. This could indicate that they want some forms of scaffolding in the event if they encounter problems during the training sessions.

Eight out of ten faculties have opted for non-term time when e-learning courses are offered. Perhaps, they had factored in the workload during term time and find that having to juggle so many things seem insurmountable. Attending classes during non-term time allows focus and concentration.

Six out of ten faculties opted for ad-hoc classes instead of 1-3 days course. The reasons could be that they prefer to have time to digest and revisit certain topic(s) before progressing to the next topics.

Seven out of ten faculties indicated a small group session over a one-to-one session. This is probably because they could learn from each other and exchange ideas.

\section{6) Incentives}

Three out of ten faculties have chosen time off another three faculties have indicated certificate of attendance as extrinsic recognitions when upgrading e-learning skills. For the former, time off is important for them possibly because they need to catch up with their committee work. For the latter, the certificate may give them the impetus to move up to the next learning level.

From the findings, the institute needs to provide more support for faculties to better implement e-learning sessions.

From the data collection, it is very clear that performance gaps exist. What is more pressing, that is, tools rated as $5=$ Poor will be the primary focused for training. Otherwise, it is very difficult for faculties to effectively design and development for e-learning activities.

Training sessions will be considered for faculties who had 
rated $1=$ very important to $2=$ important to receive tools lesson and those sessions who have more than 5 faculties as there is a minimal number requirement for a class to commence.

Based on MIKE, this paper suggests some of the potential solutions (refer to Table III below).

TABLE III: POTENTIAL SOLUTION TO NARROW THE GAPS

\begin{tabular}{|c|c|c|}
\hline Types of Driver & Findings & Potential Solutions \\
\hline $\begin{array}{l}\text { Knowledge, skills and } \\
\text { information }\end{array}$ & $\begin{array}{l}\text { Faculties rated themselves poorly for } 4 \\
\text { e-learning tools: } \\
\text { - Audio on demand; } \\
\text { - Video Editing Soft wares; } \\
\text { - Authoring tools; and } \\
\text { - Webinar; }\end{array}$ & $\begin{array}{l}\text { - Select faculties who need to be trained, are } \\
\text { serious and committed to receiving training } \\
\text { by certified e-learning instructors. } \\
\text { - Provide selected instructional strategies } \\
\text { classes so that faculties are trained and be } \\
\text { able to integrate tools and concepts, so as to } \\
\text { create more interesting e-learning classes } \\
\text { and improve on traditional classroom } \\
\text { teaching. } \\
\text { - Sharing of e-learning best practices [8]. }\end{array}$ \\
\hline Motivations and Feelings & $\begin{array}{l}\text { All faculties indicated that they would sign } \\
\text { up for the courses, thus there is no lack of } \\
\text { motivation. }\end{array}$ & $\begin{array}{l}\text { - Communicate benefits of tool via an online } \\
\text { platform, so that other faculties are aware } \\
\text { and will be motivated to upgrade their skills. }\end{array}$ \\
\hline \multirow[t]{2}{*}{$\begin{array}{l}\text { Environment, tools } \\
\text { and process }\end{array}$} & $\begin{array}{l}\text { Faculties expressed training processes to be } \\
\text { in place. }\end{array}$ & $\begin{array}{l}\text { - Provide non-term time, instructor-led, } \\
\text { face-to-face, ad-hoc classes, small group } \\
\text { setting, and weekday sessions. } \\
\text { - Technical support should be available to } \\
\text { address issues that develop in e-learning } \\
\text { delivery and access [8] }\end{array}$ \\
\hline & & $\begin{array}{l}\text { Develop E-learning regulations and } \\
\text { operational guidelines (Frequently Asked } \\
\text { Questions links). } \\
\text { - Provide } 4 \text { new e-learning tools, besides the } \\
\text { existing Collaborate. } \\
\text { - Integrate e-learning into the appraisal system }\end{array}$ \\
\hline Incentives & Time-off and Certificate of Attendance & $\begin{array}{l}\text { - Introduce new guidelines to award Certificate } \\
\text { of Attendance for Beginners, Intermediate } \\
\text { and Advance Levels. } \\
\text { - The time-off request could be parked under } \\
\text { Off- days on the Leave system. }\end{array}$ \\
\hline
\end{tabular}

\section{SUGGestions FOR Future STUdY}

For future studies, the institute may need to consider firstly, the faculties' attitudes in different schools on designing and developing e-learning sessions and students' attitudes towards e-learning sessions. If the above-mentioned studies are implemented, the findings may bring insight into resolving or minimizing the e-learning barriers.

\section{SUMMARY OF STUDY}

This study concluded with the 2 research questions being processed and answered adequately. In this study, the limitation is small sample size. However, as of now, it is sufficient to provide some understanding on how to resolve the immediate AESurvey problems.

The study's limitation is that the sample size is small. It was sufficient to provide some understanding of the AESurvey problems. Moreover, the participants are Singapore-based; hence readers should be aware that the findings maybe culture-bound and tertiary institution-bound. Nonetheless, this study's findings are reference points to other institution's faculties.

Moving forward, the management may reflect on the strategic directions of e-learning training for the entire institution and or each department. They probably should consider the recommendations so as to anchor the entire institution as a forward-looking organization that encourages faculties to receive constant skill and knowledge upgrading. The new skills and knowledge when exhibited through designing and development of engaging e-learning activities will benefit many batches of students.

\section{REFERENCES}

[1] Chartered Professional Institute Development, E-learning definition. [Online]. Available: http://www.cipd.co.uk/cipd-hr-profession/about-us, 2013.

[2] M. Hismanoglu, "E-learning practices in North Cyprus Universities Benefits, drawbacks and recommendations for effective implementation," International Education Studies, vol. 4, no. 4, pp 149-159, Nov. 2011.

[3] K. Kruse. Using the Web for Learning: Advantages and disadvantages. [Online]. Available: http://www.corebiztechnology.com/software_article_elearning_d.htm, 2004

[4] K. Becker, C. Newton, and S. Sawang, "A learner perspective on barriers to e-learning," Australian Journal of Adult Learning, vol. 53 no. 2, pp. 211-233, July 2013.

[5] A. Rossett, First things fast: a handbook for performance analysis, San Francisco, CA: Pfeiffer, 2009.

[6] K. Fee, Delivering E-learning: A complete strategy for design application and assessment, Philadephia: Kogan Page Ltd, 2009.

[7] J. W. Creswell, Educational Research: Planning, Conducting, and Evaluating Quantitative and Qualitative Research 4nd ed., Boston: Pearson. 2012

[8] A. Lee-Post, "E-Learning Success Model: an Information Systems Perspective," Electronic Journal of E-learning, vol. 7, no. 1, pp. 61-70, 2009 . 


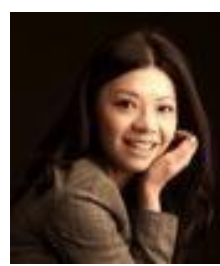

Guek Young Vanda Kwek is from Singapore. She was born on $4^{\text {th }}$ March. She completed her master of arts in instructional design and technology in 2013 from Nanyang Technological University, National Institute of Education Singapore. She graduated from Monash University, Melbourne Australia with a master in communication and media studies in 2003.

She is a pedagogic development specialist in the Center for Pedagogic Development at the Institute of Technical Education Headquarters Singapore. She was a lecturer with an Institute of Higher Learning in Singapore for almost 6 years. Her research interests are in educational technologies: usage of e-learning tools; web 2.0 tools and mobile apps for lesson delivery.

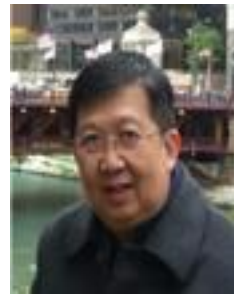

Wing Sum Cheung is an associate professor in the Learning Science and Technologies Academic Group at the National Institute of Education, Nanyang Technological University (NIE /NTU) in Singapore. He has been teaching in USA, Macau, Australia, and Singapore. His research interest has focused on a range of instructional design areas: e-learning, blended learning, asynchronous online discussion activities, and multimedia design. He has published more than 100 publications including journal articles, conference papers, and book chapters. He also conducted workshops and courses for schools, universities, industry, and government sectors. 